\title{
Single-port VATS combined with non-indwelling drain in ERAS: a retrospective study
}

\author{
Jiantian Yang ${ }^{1}$, Wencong Huang ${ }^{1}$, Peijian $\mathrm{Li}^{1}$, Huizhen $\mathrm{Hu}^{2}$, Yongsheng $\mathrm{Li}^{1}$ and Wei Wei ${ }^{1^{*}}$ (])
}

\begin{abstract}
Background: We investigated single-port video-assisted thoracoscopic surgery (VATS) combined with a postoperative non-indwelling drain in enhanced recovery after surgery (ERAS).

Methods: The clinical data of 127 patients who underwent double- and single-port VATS from January 2018 to December 2019 were analyzed retrospectively. The groups constituted 71 cases undergoing double-port and 56 cases undergoing single-port VATS (30 cases in the indwelling drain group and 26 cases in the non-indwelling drain group). The incidence of postoperative complications, pain scores, and postoperative hospital stay were compared between the two groups.

Results: Compared with the double-port group, the single-port group had shorter postoperative hospital stays and lower pain scores on the first and third postoperative days $(P<0.05)$. Pain scores on the first and third days were lower in the single-port non-indwelling drain group than in the single-port indwelling drain group $(P<0.05)$, and the postoperative hospitalization time was significantly shorter in the single-port group $(P<0.05)$. However, there was no significant difference between the two groups for operation time, incidence of complications, and pain scores 1 month after operation $(P>0.05)$.
\end{abstract}

Conclusions: The combination of single-port VATS with a non-indwelling drain can relieve postoperative pain, help patients recover quickly, and is in accordance with ERAS.

Keywords: Enhanced recovery after surgery, Single-port thoracoscopy, Non- indwelling drain

\section{Background}

Enhanced recovery after surgery (ERAS) is a new medical and nursing concept involving a series of perioperative evidence-based optimized treatments to reduce patients' physiological and psychological stress when undergoing surgery, and to achieve accelerated rehabilitation $[1,2]$. The ERAS concepts are becoming more widely used in clinical practice in many countries in Europe, with good results; however, currently, ERAS is being used relatively

*Correspondence: w7weiwei@163.com

${ }^{1}$ Department of Cardiothoracic Surgery, Huizhou Municipal Central Hospital, 41 Eling North Road, Huizhou 516001, China

Full list of author information is available at the end of the article infrequently in thoracic surgery $[3,4]$. Traditional VATS entry into the chest cavity has decreased from four to two ports and to as low a single port [5-8]. With the change from the traditional postoperative indwelling thoracic drain to the current drain-free surgery, patients' pain is further alleviated, and the impact on sensory and motor function is minimized [9-11], which is fully in line with the ERAS concepts. This study retrospectively analyzed 127 cases of double- and single-port thoracoscopic surgery, and discussed the application of single-port thoracoscopic surgery combined with a non-indwelling drain in ERAS. original author(s) and the source, provide a link to the Creative Commons licence, and indicate if changes were made. The images or other third party material in this article are included in the article's Creative Commons licence, unless indicated otherwise in a credit line to the material. If material is not included in the article's Creative Commons licence and your intended use is not permitted by statutory regulation or exceeds the permitted use, you will need to obtain permission directly from the copyright holder. To view a copy of this licence, visit http://creativecommons.org/licenses/by/4.0/. The Creative Commons Public Domain Dedication waiver (http://creativecommons.org/publicdomain/zero/1.0/) applies to the data made available in this article, unless otherwise stated in a credit line to the data. 


\section{Methods}

\section{Patients}

We reviewed the records of all patients who underwent double- and single-port thoracoscopic surgery from January 2018 to December 2019 at the Huizhou Central People's Hospital in Guangdong, China. The inclusion criteria were: 1 . age from 18 to 70 years; 2 . peripheral benign pulmonary nodules or metastases, bullae, or mediastinal masses (lung wedge resection or mass resection); 3. double- or single-port VATS; and 4. no serious heart, liver, kidney, or other underlying diseases affecting postoperative recovery or prolonging hospital stay. There were 71 cases in the double-port group and 56 cases in the single-port group. The single-port group was divided into 30 cases in the indwelling drain group and 26 cases in the non-indwelling drain group, classified on the basis of whether the chest drain was retained after surgery.

\section{Surgical technique}

All patients underwent general anesthesia with bronchial intubation and lung ventilation on the healthy side. The surgeon and first assistant stood on the same side of the patient, the patient's ventral side. An incision was made in the 4th or 5th intercostal space on the affected side. In the double-port group, we added a port for the endoscope in the 6 th or 7 th intercostal space. The incision measured approximately $3-4 \mathrm{~cm}$ along the intercostal space between anterior and axillary lines. We placed wound edge protector inside the incision, and used a $30^{\circ}$ thoracoscope for thoracic exploration. The suction device was combined with an electrocoagulation hook and ultrasonic knife for surgical operation. After the surgery, a chest tube (16 F stomach tube) was inserted into the observation port in the double-port group or into the incision in the single-port indwelling drain group. The incision was sutured closed layer by layer. In the singleport non-indwelling drain group, the drain was not fixed, and the anesthesiologist was instructed to fully inflate the lungs, then the chest tube was removed under negative pressure, and the patient entered the anesthesia resuscitation room. After patients regained consciousness, the tracheal intubation tube was removed, patients returned to the general ward for electrocardiographic monitoring, routine fluid replacement, and analgesia (flurbiprofen axetil $50 \mathrm{mg}$, intravenous injection, once every $12 \mathrm{~h}$ ). Bedside chest X-ray examination was performed the day after operation.

\section{Variables}

Operation time, postoperative hospital stay, postoperative pain score (first and third postoperative days and the first month after operation), postoperative complications (pulmonary infection, active thoracic hemorrhage, atelectasis, pneumothorax (lung compression $>30 \%$ ), incision infection) were recorded in the three groups. A 10 -point visual analogue scale (VAS) was used to evaluate postoperative pain. The score ranged from in $0-10$, where 0 indicated no pain; $1-3$ indicated mild endurable pain; 4-6 indicated moderate pain that was endurable but affected sleep quality; 7-9 indicated progressive unendurable pain; and 10 indicated severe pain. Higher scores indicated more severe pain.

\section{Statistical analysis}

All data were analyzed using SPSS 22.0 statistical software (IBM Corp., Armonk, NY). Measurement data (mean age, operative time, postoperative hospital stay, and VAS scores) were expressed as mean $\pm \mathrm{SD}$. The independent samples t-test was used to compare differences between groups. Numerical data (sex, smoking history, concurrent disease, postoperative complications) were expressed as $\mathrm{n}(\%)$, and values were compared between the groups using Fisher's exact test or the chi-square test. $\mathrm{P}<0.05$ indicated that the difference was statistically significant.

\section{Results}

The results of the comparison of the pre- and postoperative data between the double-port group and the singleport group: Table 1 shows the distributions for sex, age, history of smoking, and type of operation, and no significant differences were found $(P>0.05)$. In Table 2 , there was also no significant difference between these two groups regarding the operation time and postoperative complications $(\mathrm{P}>0.05)$. Compared with the double-port group, the postoperative hospital stay in the single-port group was slightly shorter, and the difference was statistically significant $(\mathrm{P}<0.05)$. The pain scores in the singleport group decreased significantly on the first and third postoperative days $(\mathrm{P}<0.05)$, and there was no significant difference between the two groups 1 month postoperatively $(\mathrm{P}>0.05)$. Pulmonary infection occurred in

Table 1 Demographic and clinical characteristics of double-port and single-port

\begin{tabular}{llll}
\hline Characteristics & Double-port & Single-port & P \\
\hline Sex (male/female) & $39 / 32$ & $33 / 23$ & 0.720 \\
Age (years,mean \pm SD) & $43.39 \pm 13.07$ & $41.20 \pm 11.75$ & 0.327 \\
History of smoking (yes/no) & $21 / 50$ & $17 / 39$ & 0.924 \\
Type of operation & & & 0.701 \\
Lung wedge resection n (\%) & $50(70.42)$ & $37(66.07)$ & \\
Mass resection n (\%) & $21(29.58)$ & $19(33.93)$ & \\
\hline
\end{tabular}

$\mathrm{P}<0.05$ is considered statistically significant 
six cases, and incisional wound infection occurred in two cases postoperatively, in the double-port group.

The results of the comparison of the pre- and postoperative data between the indwelling and non-indwelling drain groups in the single-port group: Table 3 shows the distributions for sex, age, history of smoking, and type of operation, and no statistically significant differences were found $(P>0.05)$. In Table 4 , there was also no significant difference in operative time and postoperative complications between the indwelling drain group and non-indwelling drain group $(\mathrm{P}>0.05)$. Comparing the indwelling drain group with the non-indwelling drain group, postoperative hospital stay in the non-indwelling drain group was obviously shorter $(\mathrm{P}<0.05)$. On the first and third postoperative days, pain scores in the nonindwelling drain group decreased significantly $(\mathrm{P}<0.05)$, but there was no significant difference in the pain scores 1 month postoperatively $(\mathrm{P}>0.05)$. Two patients developed pulmonary infection, and one patient developed incisional infection in the indwelling drain group. All three patients were treated with antibiotics, and more frequent wound disinfection and dressing changes. Complications occurred in two patients in the non-indwelling drain group. One of these patients developed pneumothorax (with 30\% lung compression) on the day of surgery. X-ray examination was repeated on the third day after conservative treatment with oxygen therapy, and images showed that the severity of the pneumothorax had decreased to 15\% lung compression. The second patient developed pulmonary infection after surgery, and was discharged after 6 days of antibiotic therapy. Both patients recovered well and did not require repeat drainage.

\section{Discussion}

ERAS is a multi-disciplinary approach involving anesthesia, nursing care, and surgery. The core concepts involve optimizing patients' perioperative treatment and

Table 2 Intraoperative and postoperative parameters

\begin{tabular}{llll}
\hline Parameters & Double-port & Single-port & P \\
\hline Operation time (min, mean \pm SD) & $54.86 \pm 13.63$ & $57.86 \pm 13.34$ & 0.216 \\
Postoperative complications n (\%) & $8(11.26)$ & $5(8.93)$ & 0.666 \\
Postoperative hospital stay (day, mean \pm SD) & $5.62 \pm 1.60$ & $4.57 \pm 2.13$ & 0.003 \\
Pain score on the first day after operation & $4.77 \pm 1.33$ & $4.05 \pm 1.51$ & 0.006 \\
Pain score on the third day after operation & $4.38 \pm 1.29$ & $3.64 \pm 1.33$ & 0.002 \\
Pain score on first month after operation & $1.23 \pm 0.93$ & $1.21 \pm 0.95$ & 0.950 \\
\hline
\end{tabular}

$\mathrm{P}<0.05$ is considered statistically significant

Table 3 Demographic and clinical characteristics of indwelling drain and non-indwelling drain

\begin{tabular}{llll}
\hline Characteristics & Indwelling drain & Non-indwelling drain & P \\
\hline Sex (male/female) & $17 / 13$ & $14 / 12$ & 0.832 \\
Age (years, mean \pm SD) & $42.70 \pm 11.98$ & $39.46 \pm 11.46$ & 0.308 \\
History of smoking (yes/no) & $11 / 19$ & $5 / 21$ & 0.236 \\
Type of operation & & & 0.384 \\
Lung wedge resection $n(\%)$ & $19(63.33)$ & $6(76.92)$ & $6(23.08)$ \\
Mass resection $n(\%)$ & $11(36.67)$ &
\end{tabular}

$\mathrm{P}<0.05$ is considered statistically significant

Table 4 Intraoperative and postoperative parameters

\begin{tabular}{llll}
\hline Parameters & Indwelling drain & Non-indwelling drain & P \\
\hline Operation time (min, mean \pm SD) & $57.67 \pm 12.91$ & $58.08 \pm 14.08$ & 0.910 \\
Postoperative complications n(\%) & $3(10)$ & $2(7.69)$ & 1.000 \\
Postoperative hospital stay (day, mean \pm SD) & $5.80 \pm 1.63$ & $3.15 \pm 1.74$ & $<0.001$ \\
Pain score on the first day after operation & $4.50 \pm 1.55$ & $3.54 \pm 1.30$ & $<0.001$ \\
Pain score on the third day after operation & $4.37 \pm 1.13$ & $2.81 \pm 1.02$ & 0.012 \\
Pain score on one month after operation & $1.37 \pm 0.93$ & $1.04 \pm 0.72$ & 0.143 \\
\hline
\end{tabular}

$\mathrm{P}<0.05$ is considered statistically significant 
nursing measures, reducing complications and patients' stress response, and accelerating rehabilitation. Thoracic surgery involves recent changes from traditional thoracoscopic surgery to single-port thoracoscopy and the introduction of $\mathrm{Da}$ Vinci robotic surgery (Intuitive Surgical, Sunnyvale, CA). Anesthesia methods have also changed to attempting anesthesia without endotracheal intubation, and postoperative management now involves analgesia without a catheter or a drain [12-15]. The results of this study further support that single-port thoracoscopic surgery combined with a postoperative non-indwelling drain can significantly reduce surgical trauma and postoperative pain. Postoperative pain relief is very important in promoting the rapid recovery of surgical patients.

The possible causes of pain after thoracic surgery arise mainly from: 1 . pain from the incision itself and compression of the intercostal nerve during and after operation; 2. an over-long or kinked chest tube after operation and stimulating the diaphragm or the parietal pleura; and 3. psychological factors; many patients fear the chest drain and incision after operation as well as the pain caused by managing the chest tube, which causes additional psychological stress. The results of this study show that performing single-port thoracoscopic surgery with no postoperative indwelling drain can decrease early postoperative pain. Postoperative pain, specifically, does not exacerbate the disease, but pain can lead to poor postoperative rehabilitation and may lead to further exacerbation of the disease. Clinically, patients in both the double-and single-port drain group must carry a drainage bottle when they get out of bed, and pain is aggravated when they walk, so most do not want to get out of bed on the first postoperative day. Additionally, postoperative pain affects coughing and sputum drainage, which cannot be effectively discharged. In elderly patients, this effect of pain greatly increases the risk of pulmonary infection, atelectasis, and other complications [16-20].

Single-port VATS without a postoperative indwelling drain eliminates having to remove the drain. Since there is no need to maintain a chest tube as long as there are no obvious abnormalities on postoperative chest X-rays, the discharge standard can be reached, postoperative hospitalization time can be shortened, and the economic burden on patients and their families can be reduced. Furthermore, not having a drain minimizes psychological stress caused by long hospital stays and increases the possibility of progressing to day surgery for these procedures, in the future.

The results of this study showed that there was no statistically significant difference in postoperative bleeding, infection, and other complications between patients in the double-port group, single-port indwelling drain group, and the single-port nonindwelling drain group. It is reasonable and feasible not to place a drain after operation, and doing so is more conducive to patients' rehabilitation. However, singleport thoracoscopic pulmonary wedge resection and mediastinal resection without retention of a chest tube still must follow certain principles. These principles are minimizing intraoperative bleeding and exudation, and avoiding senile emphysema and pulmonary infection. There must also be minimal possibility of postoperative lung leakage and pleural effusion. In the next step, we will expand the cases in each group to further study the adverse events of single-port VATS without a postoperative indwelling drain. However, whether singleport VATS combined with a non-indwelling drain can be extended to lobectomy or sleeve resection and other more involved procedures remains to be further studied $[21,22]$.

\section{Conclusions}

Single-port thoracoscopic surgery combined with nonindwelling drain after surgery can better reduce postoperative pain, shorten postoperative hospital stay, and does not increase the risk of postoperative complications, which is conducive to enhanced recovery after surgery.

\section{Abbreviations \\ VATS: Video-assisted thoracic surgery; ERAS: Enhanced recovery after surgery; VAS: Visual analogue scale.}

\section{Acknowledgements}

We thank Jane Charbonneau, DVM, from Liwen Bianji, Edanz Group China (http://www.liwenbianji.cn/ac), for editing the English text of a draft of this manuscript.

\section{Authors' contributions}

JY conducted the study and drafted the manuscript. WH and HH collected the data and performed the statistical analysis. WW completed the operation and supervised the study. PL and $Y L$ participated in the operation. All authors read and approved the final manuscript.

\section{Funding}

This study was supported by Bethune Charitable Foundation.

\section{Availability of data and materials}

The datasets used and/or analysed during the current study are available from the corresponding author on reasonable request.

\section{Declarations}

Ethics approval and consent to participate Not applicable.

Consent for publication

Not applicable.

Competing interests

The authors declare that they have no competing interests. 


\section{Author details}

'Department of Cardiothoracic Surgery, Huizhou Municipal Central Hospital, 41 Eling North Road, Huizhou 516001, China. ${ }^{2}$ Department of Pathology, Huizhou No. 1 Maternal and Child Care Service Center, Huizhou 516007, China.

Received: 12 September 2020 Accepted: 19 September 2021

Published online: 26 September 2021

\section{References}

1. Kehlet H, Wilmore DW. Multimodal strategies to improve surgical outcome. Am J Surg. 2002;183(6):630-41.

2. Wilmore DW, Kehlet H. Management of patients in fast track surgery. BMJ. 2001;322(7284):473-6.

3. Jiang Z, Li J. Current status of enhanced recovery after surgery in China. Zhonghua Wei Chang Wai Ke Za Zhi. 2016;19(3):246-9.

4. Williamsson C, et al. Impact of a fast-track surgery programme for pancreaticoduodenectomy. Br J Surg. 2015;102(9):1133-41.

5. Rocco G, Martin-Ucar A, Passera E. Uniportal VATS wedge pulmonary resections. Ann Thorac Surg. 2004;77(2):726-8.

6. Jutley RS, Khalil MW, Rocco G. Uniportal vs standard three-port VATS technique for spontaneous pneumothorax: comparison of post-operative pain and residual paraesthesia. Eur J Cardiothorac Surg. 2005;28(1):43-6.

7. Sihoe $A D$, et al. Incidence of chest wall paresthesia after video-assisted thoracic surgery for primary spontaneous pneumothorax. Eur J Cardiothorac Surg. 2004;25(6):1054-8.

8. Jiang N, Lu Y, Wang J. Is single-port video-assisted thoracic surgery for mediastinal cystectomy feasible? J Cardiothorac Surg. 2019;14(1):18.

9. LuTY, et al. Evaluation of the necessity for chest drain placement following thoracoscopic wedge resection. Surg Today. 2017;47(5):606-10.

10. Nakashima $S$, et al. Feasibility and safety of postoperative management without chest tube placement after thoracoscopic wedge resection of the lung. Surg Today. 2011;41(6):774-9.

11. Kyskan R, et al. Safety and performance characteristics of outpatient medical thoracoscopy and indwelling pleural catheter insertion for evaluation and diagnosis of pleural disease at a tertiary center in Canada. Can Respir J. 2017;2017:9345324

12. Li S, et al. New tubeless video-assisted thoracoscopic surgery for small pulmonary nodules. Eur J Cardiothorac Surg. 2017;51(4):689-93.

13. Cui F, et al. Tubeless video-assisted thoracoscopic surgery (VATS) under non-intubated, intravenous anesthesia with spontaneous ventilation and no placement of chest tube postoperatively. J Thorac Dis. 2016;8(8):2226-32.

14. Ueda K, et al. Omitting chest tube drainage after thoracoscopic major lung resection. Eur J Cardiothorac Surg. 2013;44(2):225-9 (discussion 229).

15. Yang SM, et al. Tubeless uniportal thoracoscopic wedge resection for peripheral lung nodules. Ann Thorac Surg. 2017;103(2):462-8.

16. Gottgens KW, et al. Early removal of the chest tube after complete video-assisted thoracoscopic lobectomies. Eur J Cardiothorac Surg. 2011;39(4):575-8.

17 Refai $M$, et al. The impact of chest tube removal on pain and pulmonary function after pulmonary resection. Eur J Cardiothorac Surg. 2012;41(4):820-2 (discussion 823).

18. Mao M, et al. Complications of chest tubes: a focused clinical synopsis. Curr Opin Pulm Med. 2015;21(4):376-86.

19. Li P, Li S, Che G. Role of chest tube drainage in physical function after thoracoscopic lung resection. J Thorac Dis. 2019;11(Suppl 15):S1947-50.

20. Ladan M, Petersen RH. Benefits of omitting chest drain after thoracoscopic major lung resection. J Thorac Dis. 2019;11(12):5613-5.

21 Cheng K, et al. A chest tube may not necessary in children thoracoscopic lobectomy. Medicine (Baltimore). 2019;98(26):e15857.

22. Ueda K, et al. No drain after thoracoscopic major lung resection for cancer helps preserve the physical function. Ann Thorac Surg. 2019;108(2):399-404.

\section{Publisher's Note}

Springer Nature remains neutral with regard to jurisdictional claims in published maps and institutional affiliations.
Ready to submit your research? Choose BMC and benefit from:

- fast, convenient online submission

- thorough peer review by experienced researchers in your field

- rapid publication on acceptance

- support for research data, including large and complex data types

- gold Open Access which fosters wider collaboration and increased citations

- maximum visibility for your research: over 100M website views per year

At BMC, research is always in progress.

Learn more biomedcentral.com/submissions 